\title{
Studi Komunikasi Budaya Buruh Pemetik Teh di Desa Cikendung, Slawi
}

\author{
Rocki Prasetya Suharso, Suzy Azeharie \\ rocki.915160172@stu.untar.ac.id, suzya@fikom.untar.ac.id
}

Fakultas Ilmu Komunikasi Universitas Tarumanagara Jakarta

\begin{abstract}
Culture is an accumulative store of knowledge, experience, beliefs, values, attitudes, meanings, hierarchies, religions, time choices, roles, spatial relations, broad concepts and material objects or possessions that are needed and supported by people or generations. Tea pickers in Cikendung Village, Slawi have their own culture which made their identity. The research wanted to find out how the communication culture of the tea pickers and how their social institutions. Social institutions, which means a system of behavior and relationships that are centered on specific activities in the lives of community groups, in this study are even more specific to tea pickers in Cikendung Village. The institutions that were researched are kinship, economic, religious, and somatic. This research uses a phenomenological research method by using descriptive qualitative. The research data were obtained from successful interviews with three sources, direct observations, document studies and literature studies. One of the conclusions obtained from this research is tea picker use Jawa Ngoko language to show intimacy between them, while with the foreman and guests they use Jawa Krama language to show respect. The purpose of this research is to find out the cultural communication that happened between tea pickers in Cikendung Village, Slawi.
\end{abstract}

Keywords: tea pickers, cikendung village, culture, social institutions, cultural communication.

\begin{abstract}
Abstrak
Budaya merupakan simpanan akumulatif dari pengetahuan, pengalaman, kepercayaan, nilai, sikap, makna, hirarki, agama, pilihan waktu, peranan, relasi ruang, konsep yang luas dan objek material atau kepemilikan yang dimiliki dan dipertahankan oleh sekelompok orang atau suatu generasi. Buruh pemetik teh di Desa Cikendung, Slawi memiliki budaya sendiri yang menjadikan hal itu sebagai identitas mereka. Penelitian ini ingin mengetahui bagaimanakah komunikasi budaya buruh pemetik teh dan pranata sosial mereka. Pranata yang diteliti antara lain adalah kinship, economic institutions, religious institutions, dan somatic institutions. Penelitian ini menggunakan metode penelitian fenomenologi dengan pendekatan deskriptif kualitatif. Data penelitian diperoleh dari wawancara mendalam pada tiga narasumber, pengamatan langsung, studi dokumen dan studi kepustakaan. Salah satu kesimpulan yang didapat dari penelitian ini adalah buruh pemetik teh untuk menunjukan keakraban diantara mereka maka mereka menggunakan bahasa jawa ngoko, sementara dengan mandor dan tamu menggunakan bahasa jawa krama untuk menunjukan rasa hormat. Tujuan dari penelitian ini adalah untuk mengetahui komunikasi budaya yang terjadi antara buruh pemetik teh di Desa Cikendung, Slawi.
\end{abstract}

Kata Kunci: buruh petik teh, desa cikendung, budaya, pranata sosial, komunikasi budaya.

\section{Pendahuluan}


Tanaman teh diperkenalkan di Indonesia pada tahun 1686 oleh seorang ahli botani sekaligus dokter dari Belanda bernama Andreas Cleyer di perkebunan Batavia. Saat ini, Indonesia menjadi sebagai salah satu produsen teh terbesar di dunia dengan perkebunan teh di daerah Jawa dan Sumatra (Agustina, 2010: 8).

Perkebunan teh di Indonesia umumnya dibuka pada masa Hindia Belanda, dikomandani Gubernur Jenderal Van de Bosch (1830-1870), sebagai bagian dari politik tanam paksa. Pada mulanya, bibit teh yang ditanam berasal dari Cina namun setelah bibit teh dari India masuk pada tahun 1872 maka banyak perkebunan teh memakai bibit teh India karena lebih cocok dengan iklim Indonesia (Agustina, 2010: $8)$.

Teh di perkebunan pada umumnya dipetik oleh buruh petik. Buruh merujuk pada orang yang bekerja pada usaha perorangan dan diberikan imbalan secara harian maupun borongan sesuai dengan kesepakatan kedua belah pihak, baik lisan maupun tertulis, biasanya imbalan kerja diberikan secara harian (Shanto, 2020)

Kebun teh Semugih ini dibangun ketika masa kolonialis Belanda dan warga Desa Cikendung menyebutnya sebagai salah satu peninggalan Belanda yang membawa berkah pada masyarakat sekitar. Sekarang perkebunan ini dikelola oleh PT. Perkebunan Nusantara IX. Warga desa memanfaatkan kebun tersebut sebagai sumber mata pencaharian utama karena tata letak perkebunan yang secara geografis menghasilkan hasil perkebunan yang baik (wawancara pribadi dengan Istiyani pada 27 Februari 2020 pukul 08.30).

Budaya menurut Larry A. Samovar dan Richard E. Porter dalam Liliweri adalah simpanan akumulatif dari pengetahuan, pengalaman, kepercayaan, nilai, sikap, makna, hirarki, agama, pilihan waktu, peranan, relasi ruang, konsep yang luas dan objek material atau kepemilikan yang dimiliki dan dipertahankan oleh sekelompok orang atau suatu generasi ( Liliweri, 2011:9).

Sedangkan menurut Rulli Nasrullah dalam bukunya, diungkapkan bahwa budaya merupakan nilai-nilai yang muncul dari proses interaksi antar individu yang diakui baik secara langsung atau tidak seiring dengan waktu yang dilalui dalam interaksi tersebut dan terkadang sebuah nilai tersebut berlangsung di dalam alam bawah sadar individu dan diwariskan pada generasi berikutnya (Nasrullah, 2014:15). Budaya memungkinkan manusia beradaptasi dengan lingkungannya. Dan komunikasi memainkan peran penting dalam proses adaptasi ini. Karena dengan berkomunikasi maka suatu budaya dapat dipertahankan dan diteruskan pada generasi yang lebih muda.

Penulis melakukan penelitian terhadap komunikasi budaya yang ada pada buruh pemetik teh di Perkebunan Cikendung ini. Bagaimana nilai, sikap, pengalaman buruh dan komunikasi di antara mereka. Selain itu penulis ingin meneliti bagaimanakah pranata sosial buruh pemetik teh ini. Pranata sosial digambarkan menurut Koentjaraningrat adalah suatu sistem tata kelakuan dan hubungan yang berpusat pada aktivitas-aktivitas khusus dalam kehidupan masyarakat. Pengertian ini menekankan pada sistem tata kelakuan atau norma-norma untuk memenuhi kebutuhan. Atau diartikan juga sebagai unsur-unsur yang mengatur perilaku warga masyarakat yang berinteraksi (Koentjaraningrat, 2015:135).

Dirangkum bahwa budaya merupakan adat-istiadat dan kebiasaan yang sudah ada dari generasi sebelumnya yang dimiliki oleh sekelompok orang sehingga menjadi suatu budaya atau tradisi sendiri. Hubungan dengan penelitian yang dilakukan penulis adalah kelompok buruh pemetik teh merupakan suatu paguyuban yang memiliki tata-cara mereka sendiri yang diturunkan dari generasi sebelumnya. Dalam 
penelitian ini penulis melakukan studi komunikasi budaya terhadap buruh pemetik teh di perkebunan teh Semugih, Desa Cikendung, Slawi.

Tujuan dari penelitian ini adalah untuk mengetahui bagaimanakah komunikasi budaya yang terjadi antara para buruh pemetik teh di desa Cikendung, Slawi dan mengetahui pranata-pranata sosial yang terjadi dalam buruh pemetik teh di desa Cikendung, Slawi.

\section{Metode Penelitian}

Penulis menggunakan pendekatan metode kualitatif deskriptif dalam pendekatan fenomenologi.

Menurut John W. Creswell dalam Herdiansyah, penelitian kualitatif adalah proses penyelidikan berdasarkan tradisi metodologi penyelidikan yang berbeda yang mengeksplorasi masalah sosial atau manusia (Herdiansyah, 2010:8).

Sementara menurut Lexy J. Moleong penelitian kualitatif adalah penelitian yang bertujuan untuk memahami fenomena yang dialami oleh subjek penelitian melibatkan perilaku, persepsi, motivasi, tindakan dan lalu dideskripsikan dalam bentuk kata-kata pada suatu konteks khusus dan menggunakan metode alamiah (Moleong, 2009:6).

Sedangkan menurut Saryono, penelitian kualitatif berfungsi untuk menemukan, menyelidiki, menggambarkan serta menjelaskan keistimewaan dari pengaruh sosial yang tidak dapat digambarkan melalui pendekatan kuantitatif (Saryono, 2010:1).

Dari beberapa teori di atas, dapat dirangkum bahwa penulis menggunakan jenis metode penelitian kualitatif karena dinilai paling tepat untuk mengambil data dan mengetahui bagaimana komunikasi budaya terjadi pada buruh pemetik teh di Desa Cikendung, Slawi.

Menurut Martin Heidegger dalam Jonathan A Smith konsep fenomenologi adalah mengenai orang yang selalu tidak dapat dihapuskan dari dalam konteks dunianya dan intersubyektifitas (Smith, 2009:17).

Sedangkan menurut Nana Syaodih Sukmadinata, pendekatan fenomenologi memiliki tujuan untuk mengungkapkan pencarian arti dan pengalaman hidup seseorang (Sukmadinata, 2010:63).

Dirangkum dari beberapa pengertian fenomenologi di atas, penelitian fenomenologi merupakan varietas dari penelitian kualitatif yang berfokus pada aspek subyektif dari perilaku orang, memahami arti peristiwa dan kaitannya terhadap orang-orang yang berada dalam situasi tersebut. Oleh karena itu, penulis menggunakan metode fenomenologi untuk mendapatkan data dan informasi yang dibutuhkan dalam penelitian ini.

\section{Hasil Penemuan dan Diskusi}

\section{Kebun teh Semugih di Desa Cikendung.}

Kebun teh Semugih yang berada di Desa Cikendung merupakan peninggalan dari zaman Belanda yang menjadi sumber mata pencaharian bagi warga sekitar Desa Cikendung, Slawi. Oleh karena itu, rata-rata pekerjaan warga sekitar adalah sebagai buruh pemetik teh. Buruh-buruh pemetik teh Desa Cikendung berangkat kerja pukul 05.30 WIB dan selesai kerja pada pukul 13.00 WIB, setelah selesai kerja biasanya 
mereka langsung pulang dan melanjutkan kegiatan sebagai ibu rumah tangga. Kebun teh Semugih ini juga merupakan salah satu kebun yang dikelola oleh PT. Perkebunan Nusantara IX. Sistem kerja buruh teh di perkebunan Semugih ini semua berdasarkan peraturan yang diciptakan oleh PTPN IX supaya memiliki sistem gaji yang jelas. Sistem gaji yang berlaku adalah tiap buruh pemetik akan dibayar setiap dua minggu sekali tergantung berat total hasil panen dan kualitas daun tehnya (wawancara pribadi dengan Istiyani melalui Video call WhatsApp pada 27 Mei 2020 08.30 WIB).

\section{Komunikasi Budaya Buruh Pemetik Teh.}

Komunikasi yang terjadi dalam buruh pemetik teh merupakan hal yang sangat penting untuk menunjukan sifat keramahan terhadap sesama warga desa. Baik buruh petik teh maupun semua warga di desa tersebut, mereka mengutamakan sopan-santun dan keramah-tamahan karena sudah menjadi budaya dan tradisi mereka untuk bersikap santun apabila bercakap dengan sesama. Komunikasi di Desa Cikendung menggunakan bentuk verbal. Apabila berkomunikasi dengan sesama pemetik teh, maka pihak komunikator maupun komunikan menggunakan bahasa Jawa Ngoko karena dinilai lebih akrab dan tidak kaku. Lain halnya apabila warga Desa Cikendung berkomunikasi dengan warga desa lain ataupun wisatawan luar kota. Mereka akan menggunakan bahasa Jawa Krama Alus dan bahasa Indonesia yang baku untuk menunjukan rasa hormat, dan terbuka (wawancara pribadi dengan Prihati melalui Video call WhatsApp pada 27 Mei 2020 pukul 14.30 WIB).

Menurut Koentjaraningrat terdapat tujuh unsur kebudayaan, antara lain adalah bahasa, sistem pengetahuan, organisasi sosial, sistem peralatan hidup dan teknologi, sistem mata pencaharian hidup, sistem religi dan kesenian. Tiap unsur kebudayaan universal menjelma dalam tiga wujud kebudayaan yang terurai di atas, yaitu wujudnya berupa sistem budaya, sistem sosial, dan berupa unsur-unsur kebudayaan fisik (Koentjaraningrat, 2015:165). Setelah manusia tersebut berinteraksi secara intensif maka sifat khas dari unsur-unsur kebudayaan masing-masing berubah menjadi unsur kebudayaan campuran (Azeharie, 2019).

1. Bahasa

Warga Desa Cikendung memiliki bahasa Jawa Ngoko yang khas dengan logat Ngapak seperti daerah Tegal, dan Pemalang. Akan tetapi apabila warga Desa tersebut berkomunikasi dengan orang luar dari Desa maka akan menggunakan bahasa Jawa Krama Alus dan bahasa Indonesia yang baku untuk menunjukan rasa hormat. Menurut Istiyani, apabila berbicara dengan orang luar menggunakan bahasa Jawa Ngoko, maka akan berkesan bahwa ia seakan-akan memandang rendah orang luar tersebut. Berbeda apabila menggunakan bahasa Jawa Ngoko dengan warga Desa Cikendung tersebut, maka akan terkesan akrab seperti keluarga sendiri (wawancara pribadi dengan Istiyani melalui Video call WhatsApp pada 27 Mei 2020 pukul 09.15 WIB).

\section{Sistem Pengetahuan}

Buruh petik teh harus menguasai pengetahuan dasar akan keadaan alam sekitar selain berwawasan tentang teknis pemetikan teh, seperti kapan saatnya 
melakukan rotasi dan memanen lahan yang lainnya, perkiraan dalam sehari berapa jumlah daun teh yang dapat dipetik dan pengetahuan tentang cara mengelola daun teh tersebut untuk dikonsumsi sendiri. (wawancara pribadi dengan Prihati melalui Video call WhatsApp pada 27 Mei 2020 pukul 15.00WIB).

\section{Organisasi Sosial}

Organisasi sosial yang terdapat di Desa Cikendung tidak banyak, yaitu perkumpulan ibu-ibu pengajian, paguyuban buruh petik teh dan perkumpulan arisan. Buruh pemetik teh ini biasanya mengaji dua kali seminggu tiap hari selasa dan jumat, mereka melakukan kegiatan pengajian di rumah salah satu pemetik dalam kelompok itu, lalu akan bergantian sehingga tidak hanya di satu rumah saja. Apabila arisan dilakukan sebulan sekali, dan berkumpul di rumah yang sebelumnya mendapatkan arisan tersebut, untuk biaya arisan mereka akan membayar sebesar RP.100.000. Organisasi tersebut terbentuk karena sifat kekeluargaan yang terdapat pada sesama buruh petik teh. Dengan rasa kekeluargaan yang kental maka perkumpulan ibu-ibu pengajian, sampai perkumpulan arisan dapat terbentuk sendiri (wawancara pribadi dengan Prihati melalui Video call WhatsApp pada 27 Februari 2020 pukul 15.00 WIB).

\section{Teknologi}

Buruh petik teh di Desa Cikendung, Slawi menggunakan teknologi sederhana namun dapat membantu meringankan pekerjaan mereka. Mulai dari alat gunting yang telah dimodifikasi sendiri, hingga pakaian lengan panjang yang memiliki tujuan untuk melindungi tubuh mereka (wawancara pribadi dengan Istiyani melalui Video call WhatsApp pada 27 Mei 2020 pukul 09.15 WIB).

\section{Sistem Mata Pencaharian Hidup}

Menjadi buruh teh merupakan sumber mata pencaharian hidup bagi para warga di Desa Cikendung, Slawi. Ia juga menyampaikan berbagai jenis daun teh yang bila dijual harganya yang dapat mencapai satu juta rupiah setiap kilogram. Terdapat juga hasil teh yang diekspor oleh PTPN IX ini, jenis teh tersebut adalah teh hitam yang biasanya digunakan oleh warga desa sebagai obat (wawancara pribadi dengan Prihati melalui Video call WhatsApp pada 27 Mei 2020 pukul 15.15 WIB).

Gambar 1. Pucuk daun teh yang dipetik sebagai sumber penghasilan bagi buruh petik teh di Desa Cikendung, Slawi. 




Sumber: Dokumentasi Penulis pada 26 Februari 2020 pukul 08.00 WIB

\section{Sistem Religi}

Sebagian besar warga desa menganut agama Islam dan ada beberapa keluarga yang beragama Kristen Protestan. Selain itu, Istiyani juga mengatakan bahwa semua warga desa memiliki kepercayaan tersendiri terhadap Gunung Slamet (wawancara pribadi dengan Istiyani melalui Video call WhatsApp pada 27 Mei 2020 pukul 09.30 WIB).

\section{Kesenian}

Kesenian yang terdapat pada warga Desa Cikendung adalah seni yang berupa kerajinan tangan dari kayu. Menurut Istiyani, kerajinan tersebut dibuat oleh warga desa sebagai hiasan di rumah mereka untuk menciptakan kesan yang baik apabila ada yang bertamu (wawancara pribadi dengan Istiyani melalui Video call WhatsApp pada 27 Mei 2020 pukul 09.30 WIB).

Gambar 2. Bentuk meja dan kursi yang dipahat oleh laki-laki warga Desa

\section{Cikendung.}

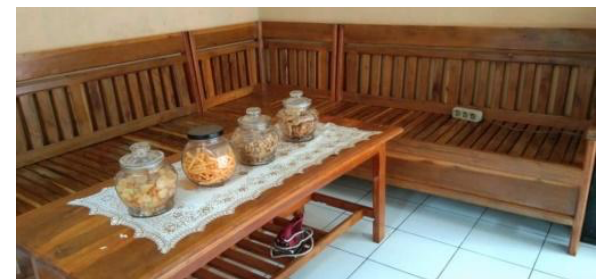

Sumber: Dokumentasi Narasumber.

\section{Pranata Sosial}

Pranata sosial menurut Koentjaraningrat adalah suatu sistem tata kelakuan dan hubungan yang berpusat pada aktivitas-aktivitas khusus dalam kehidupan masyarakat. Pengertian ini menekankan pada sistem tata kelakuan atau norma-norma untuk memenuhi kebutuhan. Dapat diartikan juga oleh Koentjaraningrat sebagai unsur-unsur yang mengatur perilaku para warga masyarakat yang berinteraksi. 
Rocki Prasetya Suharso, Suzy S. Azeharie: Studi Komunikasi Budaya Buruh Pemetik Teh di Desa Cikendung, Slawi

\section{a. Kinship atau Domestic Institutions}

Para buruh petik teh ini menggunakan sistem kerja tanpa upah pasti yang disebut remojong oleh warga Desa Cikendung. Remojong sendiri memiliki arti bahwa para warga desa termasuk buruh petik teh saling membantu satu sama lain dengan upah yang tidak berupa uang, melainkan tenaga kerja balik sebagai bentuk ucapan terima kasih (wawancara dengan Istiyani melalui Video call WhatsApp pada 27 Mei 2020 Pukul 10.00).

\section{b. Economic Institutions}

Sumber mata pencaharian utama bagi warga Desa Cikendung terdapat di perkebunan teh, dimana siapa saja bisa menjadi buruh petik teh. Bahkan Prihati bercerita bahwa ia sudah menjadi buruh petik sejak masih kecil karena menghasilkan pemasukan untuk membantu ekonomi rumah (wawancara pribadi dengan Prihati melalui Video call WhatsApp pada 27 Mei 2020 pukul 15.15 WIB).

\section{c. Religious Institutions}

Semua warga Desa Cikendung termasuk buruh petik teh memiliki kepercayaan terhadap Gunung Slamet yang memberikan mereka berkah dan rezeki (wawancara pribadi dengan Prihati melalui Video call WhatsApp pada 27 Mei 2020 pukul 15.15 WIB).

d. Somatic Institutions

Rata-rata buruh teh perempuan menggunakan rias wajah sebelum berangkat kerja dengan tujuan yang berbeda-beda. Ada yang menyebutkan untuk kesehatan, ada yang menyebutkan karena sudah terbiasa dari kecil ada juga yang meyebutkan bahwa rias wajah merupakan hobi supaya enak dilihat. Selain rias wajah, tidak sedikit pula ibu-ibu pemetik teh ketika sedang beristirahat pada pukul 08.00 WIB, mereka akan merokok. Sudah menjadi tradisi masyarakat Desa Cikendung merokok menunjukan arti sudah beranjak dewasa. Hal itu tidak hanya dilakukan oleh buruh petik teh, melainkan seluruh warga Desa Cikendung, terutama bagi para anak laki-laki yang baru saja disunat mereka biasanya akan merokok untuk menunjukan bahwa mereka sudah beranjak dewasa ( wawancara pribadi dengan Istiyani melalui Video call WhatsApp pada 27 Mei 2020 pukul 09.30 WIB).

\section{Simpulan}

Buruh pemetik teh di perkebunan teh Semugih, Desa Cikendung, Slawi memiliki tradisi dan budaya sendiri yang sudah ada dari zaman dahulu yang diturunkan hingga generasi sekarang. Komunikasi budaya yang terjadi meliputi semua unsur kebudayaan menurut Koentjaraningrat

Pranata sosial yang terdapat pada buruh pemetik teh di desa tersebut meliputi kinship atau domestic institutions, economic institutions, religious institutions dan somatic institutions. Mereka memiliki sistem tata kelakuan yang berpusat pada aktivitasaktivitas khusus dalam kehidupan kelompok buruh pemetik teh di Desa Cikendung.

\section{Ucapan Terima Kasih}

Penulis mengucapkan terima kasih yang sebesar-besarnya terhadap semua pihak yang telah membantu penulis dalam menyelesaikan penelitian ini. 


\section{Daftar Pustaka}

Agustina, Maria. (2010). 1001 teh. Yogyakarta: CV. ANDI OFFSET.

Azeharie, S. (2016). Pola Komunikasi Antara Pedagang dan Pembeli di Desa Pare, Kampung Inggris Kediri. Jurnal Komunikasi Volume. 7 No 2.

Flower, Larkin and Smith. (2009). Interpretative Phenomenological Analysis: Theory, Method and Research. Los Angeles: SAGE Publication.

Herdiansyah, Haris. (2010). Metode Penelitian Kualitatif untuk Ilmu-ilmu Sosial. Jakarta: Salemba Humanika.

Koentjaraningrat. (2015). Pengantar Ilmu Antropologi. Jakarta: Rineka Cipta.

Liliweri. (2011). Komunikasi Serba Ada Serba Makna.Jakarta : Prenada Media Group.

Moleong, Lexy J. (2009). Metodologi Penelitian Kualitatif. Bandung: PT. Remaja Rosdakarya

Nasrullah. (2014). Teori dan Riset Media Siber (Cybermedia). Jakarta: Kencana Prenadamedia Group..

Saryono. (2010). Metode Penelitian Kualitatif. Bandung: PT. Alfabeta.

Shanto. (2016). Pengertian buruh. https://spn.or.id/pengertian-buruh/

Sukmadinata. (2010). Metode Penelitian Pendidikan. Bandung: PT Remaja Rosdakarya. 